(C) 2018. This manuscript version is made available under the CC-BY-NC-ND 4.0 license http://

creativecommons.org/licenses/by-nc-nd/4.0/

\title{
Epidemiology of morbidity and mortality in US and Canadian recreational scuba diving
}

\section{Buzzacott, P. and Schiller, D. and Crain, J. and Denoble, P.}

\begin{abstract}
Objectives: This study investigates morbidity and mortality suffered by divers in the US and Canada.
\end{abstract}

Study design: Prospectively recruited probability weighted sample for estimating the national burden of injury, and a weighted retrospective survey for estimating exposure.

Methods: The National Electronic Surveillance System (NEISS) and Canadian Hospitals Injury Reporting and Prevention Program (CHIRPP) were searched for scuba diving injuries. The Divers Alert Network (DAN) diving fatality database was searched for deaths and Sports and Fitness Industry Association (SFIA) estimates for diving were obtained from annual surveys.

Results: In the US there were an estimated 1,394 emergency department (ED) presentations annually for scuba-related injuries. The majority (80\%) were treated and/or released. There were an estimated 306 million dives made by US residents 2006-2015 and concurrently 563 recreational diving deaths, a fatality rate of 0.18 per $10^{5}$ dives and 1.8 per $10^{5}$ diver-years. There were 658 diving deaths in the US 2006-2015 and 13,943 ED presentations for scuba injuries, giving a ratio of 47 diving deaths in the US for every 1,000 ED presentations. There were 98 cases of scuba-related injuries identified in the CHIRPP data. The prevalence of scuba-related injuries for patients aged 3-17 years was 1.5 per $10^{5}$ cases, and the prevalence of scuba related-injuries to patients $18-62$ years was 16.5 per $10^{5}$ cases.

Discussion: In Canada and the US only one out of every 10,000 ED presentations is due to a scuba-related injury. That there are 47 deaths for every 1,000 ED presentations speaks to the relatively unforgiving environment in which scuba diving takes place. At 1.8 deaths per million recreational dives, mortality in scuba diving is nonetheless relatively low.

Keywords: Barotrauma, Canadian Hospitals Injury Reporting and Prevention Program, decompression, Emergency Department, fatality rate, National Electronic Surveillance System. 


\section{Epidemiology of morbidity and mortality in US and Canadian recreational scuba diving}

\section{INTRODUCTION}

Scuba diving is a popular recreational pursuit enjoyed by millions of divers in the US and Canada, ${ }^{1}$ though it exposes divers to stresses that sometimes result in injuries. The pressure exerted upon a diver increases by one atmosphere for every 10 metres of seawater depth, effectively doubling when a diver descends from the surface to $10 \mathrm{~m}$ depth in the sea. Once a diver is submerged and then breathing, gas (usually air) is delivered at a pressure equivalent to the ambient pressure at whatever depth the diver is at. Therefore, the deeper a diver dives, the faster the air in the scuba tank is consumed and the more gas is taken-up by the diver's tissues. Immersion also contributes to the physiological stresses a diver experiences.

Drowning is the leading cause of death in diving, often after running out of gas, followed by cardiac causes and arterial gas embolisms. ${ }^{2}$ Barotrauma from expanding gas during ascent, or from compression of the air spaces within the diver during descent, are the most common injuries reported to Divers Alert Network (DAN) each year through the 24-hours diving Emergency Helpline. ${ }^{3}$ DAN is a not-for-profit diving safety organization that provides assistance to divers in need of medical help, monitors diving injuries, studies their causes and provides training in first aid and diving medicine.

Decompression sickness (DCS) and arterial gas embolisms (AGE) are commonly referred to collectively as Decompression Illness (DCI). Other hazards faced by scuba divers include hazardous marine life encounters, trauma, sprains and strains from heavy scuba equipment, boating injuries, falls while wearing scuba equipment and a myriad of other injuries. The risk of diving injuries for the population is not available because of a lack of data. The incidence data for diving injuries among recreational divers is incomplete because they are not mandatory reportable, unlike in military or scientific divers. There are two main rates of interest in diving; the number of injuries or deaths per $10^{5}$ dives, and per $10^{5}$ divers per year. ${ }^{4}$

\section{Morbidity rates}

Dive conditions and dive populations vary across the world and, thus, injury rates may vary too. Over the 12 year period 1995-2007 the number of divers treated for DCI in Australia numbered $3,558 .{ }^{5}$ Over the same period participation in sport surveys suggested this amounted to a DCI rate of 10.7 cases per $10^{5}$ dives. ${ }^{5}$ In Canada the number of air fills sold 
within a defined region was used to estimate that 146,291 dives had been made between 1999-2000, during which time there were 14 known injuries, amounting to a rate of 9.7 cases per $10^{5}$ dives. $^{6}$ A similar, earlier study at a military base in Okinawa noted 94 cases of DCI between 1989-1995 and an estimated rate of 13.4 cases per $10^{5}$ dives. $^{7}$ In the warmer Caribbean a study conducted in 1989-1990 noted 77,680 dives and 7 cases of decompression sickness (DCS), giving a rate of 9.0 cases per $10^{5}$ dives. ${ }^{8}$ A 1990 British study of 36,434 divers found 6.7 case of DCI per $10^{5}$ dives. $^{9}$ In Japan a survey of 3,078 recreational divers between 1996-2001 found a reported incidence of DCS at 5.2 cases per $10^{5}$ dives and a combined incidence of ear or sinus barotrauma, or DCS, of 49.3 injuries per $10^{5}$ dives. $^{10}$ Numerous smaller studies have reported rates outside the above range, possibly due to wider confidence intervals associated with small sample sizes. In diving morbidity research to date, efforts have focussed on diving cohorts, for example customers of dive businesses in a geographically defined area, or members of DAN. To our knowledge no previous research has extracted scuba diving injury cases from much broader public health data.

\section{Mortality rates}

Using sports survey data, between 2002 and 2006 the fatality rate in Australia was estimated at 0.57 per $10^{5}$ dives. ${ }^{5}$ This was lower than found after counting the number of air fills sold, in British Columbia 1999-2000 at 2.05 per 10 dives, or in Okinawa 1989-1995 at 1.3 per $10^{5}$ dives. ${ }^{6,7}$ At a popular flooded quarry in the United Kingdom mortality over a five year period was observed to be 2.9 per $10^{5}$ visiting divers. ${ }^{11}$ Among members of the Divers Alert Network 2000-2006, the overall mortality rate was found to be 16.4 deaths per $10^{5}$ insured person-years but mortality per $10^{5}$ dives was not available due to the lack of exposure data. ${ }^{12}$ More recently, DAN Japan reported a lower membership mortality rate over 2004-2012 of 6.9 deaths per $10^{5}$ member years, while in Australia, similar to the result above, a rate of 0.5 deaths per $10^{5}$ dives was based on annual surveys of Australian residents. ${ }^{3,13}$

\section{Preventive efforts}

Since the development and widespread adoption of the internet divers have greater access to diving safety information than at any time previously. Concurrent with the growth in internet access, scuba diving equipment has continued to improve (for example modern diving 
computers are now worn by the majority of divers), diver training is more widely available today than ever before, and professional dive guides can be located as easily as clicking a mouse. It is, therefore, possible that diving is safer today than ever. What is not known are the current rates of morbidity and mortality suffered by divers in the US and Canada each year. This study aimed to determine scuba diving related morbidity and mortality based on publicly available ED in the US and Canada.

\section{METHODS}

In the US the Consumer Product Safety Commission (CPSC) maintain the National Electronic Surveillance System (NEISS), a national register of Emergency Department (ED) presentations at around 100 hospitals in US and US Territories. The data are sample probability weighted to reflect the $\sim 5000$ EDs in the wider US and US territories, deidentified, and each year the previous year's data are made publically available through the CPSC website. NEISS data have been used to describe a wide variety of injuries such as those resulting from paintball guns, ${ }^{14}$ surfing, ${ }^{15}$ and burns. ${ }^{16}$ NEISS data for 2006-2015 were obtained from the CPSC website (www.cpsc.gov/en) and imported into Windows Notebook as tab-delineated text. Product code 1275 identifies injuries related to scuba in the NEISS dataset. ${ }^{17}$ Cases involving product code 1275 were identified using SAS ver 9.4 (SAS, Cary, NC). A search for the word "scuba" in the case description field identified eight further cases, and manually checking the case descriptions for cases identified by product code 1275 found eight misclassified cases which were excluded. National estimates arising from NEISS data are considered by the Centers for Disease Control and Prevention as unstable and potentially unreliable when:

- the estimate is less than 1,200

- or the number of records used is less than 20 , or

- the coefficient of variation (CV) exceeds $30 \%{ }^{18}$

The Canadian Hospitals Injury Reporting and Prevention Program (CHIRPP) supplied data concerning scuba diving injuries in children and adults presenting at emergency Departments at 11 paediatric and five general hospitals across Canada between 1990-2015. Since commencing data collection in April 1990, CHIRPP data have been used to describe various injuries including those from curling, ${ }^{19}$ off-road vehicle use, ${ }^{20}$ and martial arts. ${ }^{21}$ A fuller 
description of CHIRPP data collection methods, including the names of participating hospitals, can be found here. ${ }^{22}$ Records with the following criteria were assessed for inclusion in the study:

- $\quad$ Records with Factor code "1167 Scuba Diving" (Direct Cause, Mechanism Factor, Contributing Factor, Breakdown Factor, and/or Factor codes 1-6)

- $\quad$ Cases in which the patient's narrative contained a relevant text string: SCUBA, S.C.U., S C U, PLONGEE SOUS, BREATHING APPARATUS, or BREATHING APP

Cases associated with the following activities were excluded from the study, via case-by-case manual cleaning:

- $\quad$ Cases where a non-scuba breathing apparatus was involved (e.g. fire-fighting equipment)

- $\quad$ Mis-coded or other inapplicable cases

The Divers Alert Network (DAN) diving fatality database was searched for deaths involving divers that occurred in the US or Canada between 2006-2015. The data collection process at DAN is described in detail in the DAN Annual Diving Report. ${ }^{3}$ In brief, diving fatalities are identified through internet alerts, news, forums or reports from affiliated organizations such as County Coroners, Public Safety Divers, Medical Examiners or members of the public. Other sources for notification regarding fatalities include notifications from families of DAN members and friends and acquaintances of the deceased who are aware of DAN's data collection efforts. Most scuba-related deaths in the US are investigated by local law enforcement agencies or the US Coast Guard (USCG) and are subjected to autopsies. Each state in the US has its own set of regulations regarding the release of information in addition to compliance to the federally mandated HIPAA (Health Insurance Portability and Accountability Act of 1996) Privacy Rule. Some states consider investigation and medical examiner's reports to be public information and are released easily while others are governed by more stringent privacy laws. In addition, within each state, sometimes the regulations (and, hence, ease in procuring reports) can also vary from county to county. The majority of diving deaths in the US occur in Florida and California, and these two states have relatively straightforward protocols for requesting and obtaining copies of reports. Local investigating agencies (sheriff and police departments) also often release reports under the Freedom of Information Act (FOIA).

The Sports and Fitness Industry Association (SFIA) publish annual participation rates following web-based surveys with the sample weighted to align with the US population 
according to the US Bureau of Census. ${ }^{1}$ Weighting variables include age, gender, income, household size, region, population density and panel join data. Reports covering 2006-2015 resulted from 383,389 interviews during participation in an annual survey.

Both the NEISS and SFIA data are publically available, the DAN fatality data was collected and analysed under approval from the Divers Alert Network Institutional Review Board (Approval \#011-016) and the CHIRPP data were de-identified before analysis, therefore, the CHIRPP determined separate IRB approval was not required in this instance.

\section{Analysis}

The coefficient of variance for the 2006-2015 pooled data was 0.2897. National estimates were calculated by summing the weights for relevant cases (e.g. the sum of all weights for males). Means, standard deviations and confidence intervals were calculated using SAS ver 9.4 (Cary, NC). The SFIA two year rolling average estimates for number of participants from 2008 onwards were un-averaged by doubling each estimate and subtracting the previous year's estimate. Annual number of estimated dives were supplied by SFIA.

\section{RESULTS}

\section{USA}

There were 378 individual ED presentations in the NEISS data out of 3,799,805 cases $(0.0099 \%)$, equating to an estimated 13,943 cases nationally out of $140,624,966(0.0099 \%)$, $10,503(75 \%)$ male and $3440(25 \%)$ female. On average there were an estimated 1,394 presentations for scuba-related injuries per year (95\% CI 1125-1663).

Table 1 presents, by year and overall, the estimated number of divers, dives, fatalities and ED presentations in the US 2006-2015. 
Table 1: Estimated number of divers, dives, fatalities and ED presentations in the US 2006-2015

\begin{tabular}{|c|c|c|c|c|c|c|c|c|c|}
\hline Year & $\begin{array}{c}\text { Total } \\
\text { Interviews }\end{array}$ & $\begin{array}{c}\text { US } \\
\text { Population }\end{array}$ & $\begin{array}{l}\text { Estimated } \\
\text { Number } \\
\text { of Divers } \\
\text { (x1000) }\end{array}$ & $\begin{array}{c}\text { Estimated } \\
\text { Number of } \\
\text { Dives }\end{array}$ & $\begin{array}{c}\text { NEISS } \\
\text { Estimate } \\
\text { Total ED } \\
\text { presentations }\end{array}$ & $\begin{array}{c}\text { NEISS } \\
\text { Estimate } \\
\text { Scuba ED } \\
\text { Presentations }\end{array}$ & $\begin{array}{c}\text { Number } \\
\text { recreational } \\
\text { diving } \\
\text { deaths }\end{array}$ & $\begin{array}{c}\text { Foreign } \\
\text { diving } \\
\text { deaths } \\
\text { in US }\end{array}$ & $\begin{array}{c}\text { Non- } \\
\text { recreational } \\
\text { diving } \\
\text { deaths }\end{array}$ \\
\hline 2006 & 60,169 & $274,110,000$ & 2,912 & $33,296,950$ & $13,232,263$ & 2,034 & 51 & 2 & 4 \\
\hline 2007 & 40,794 & $276,796,000$ & 2,965 & $33,296,950$ & $13,232,338$ & 1,327 & 77 & 1 & 6 \\
\hline 2008 & 41,500 & $279,568,000$ & 3,216 & $34,063,443$ & $14,694,928$ & 1,247 & 65 & 1 & 3 \\
\hline 2009 & 40,141 & $281,658,000$ & 2,723 & $34,470,468$ & $13,966,898$ & 1,458 & 58 & 2 & 17 \\
\hline 2010 & 38,742 & $283,743,000$ & 3,153 & $32,809,633$ & $14,694,928$ & 1,131 & 56 & 0 & 12 \\
\hline 2011 & 38,172 & $285,753,000$ & 2,579 & $29,251,205$ & $14,162,084$ & 570 & 74 & 0 & 9 \\
\hline 2012 & 42,356 & $287,138,000$ & 2,982 & $29,133,845$ & $14,614,128$ & 1,365 & 55 & 1 & 10 \\
\hline 2013 & 19,240 & $290,001,000$ & 3,366 & $27,948,960$ & $14,033,745$ & 1,569 & 47 & 1 & 11 \\
\hline 2014 & 29,610 & $292,064,000$ & 2,924 & $25,910,356$ & $13,860,956$ & 1,190 & 50 & 0 & 10 \\
\hline 2015 & 32,658 & $294,141,894$ & 3,624 & $25,992,577$ & $14,132,697$ & 2,052 & 30 & 0 & 5 \\
\hline Total & 383,389 & $2,844,972,894$ & 30,444 & $306,174,386$ & $140,624,966$ & 13,943 & 563 & 8 & 87 \\
\hline
\end{tabular}


Estimated mean age of those presenting for scuba-related injuries was 38.0 (95\% CI 34.441.7) overall, males averaged an estimated 37.1 years (95\% CI 33.1-41.2) and females 40.7 years (95\% CI 32.5-49.0). Raw diagnoses are shown in Table 2. National estimates were not made because cell-counts were nearly all $<20$.

Table 2: Diagnoses by raw number $(\mathrm{n}=378)$

\begin{tabular}{lc}
\hline Diagnosis & Raw n $(\%)$ \\
\hline Aspirated foreign object & $2(1)$ \\
Barotrauma & $12(3)$ \\
Cellulitis & $10(3)$ \\
Contusions, Abrasions & $17(4)$ \\
Decompression Sickness & $22(6)$ \\
Dental injury & $2(1)$ \\
Dermatitis, Conjunctivitis & $5(1)$ \\
Ear Pain & $17(4)$ \\
Foreign body & $2(1)$ \\
Fracture & $14(4)$ \\
Headache & $6(2)$ \\
Hemorrhage & $3(1)$ \\
Internal organ injury & $31(8)$ \\
Laceration & $17(4)$ \\
Marine life injury & $3(1)$ \\
Other/Not Stated & $64(17)$ \\
Otitis & $50(13)$ \\
Pain / ChestPain & $48(13)$ \\
Paralysis / numbness & $4(1)$ \\
Poisoning & $3(1)$ \\
Puncture & $7(2)$ \\
Shortness of breath & $4(1)$ \\
Strain or Sprain & $19(5)$ \\
Submersion (including Drowning) & $16(4)$ \\
\hline Total & $378(100)$ \\
\hline
\end{tabular}

Where race was identified in NEISS, 93\% were classes as white whereas the US Census Bureau identify $77 \%$ of the population as white, ${ }^{23}$ (though the racial distribution among recreational divers is uncertain). Affected body parts are presented in Table 3. Once again raw prevalence is presented because the majority of cell counts were lower than 20 .

Table 3: Body part affected by scuba-related injury $(\mathrm{n}=378)$

\begin{tabular}{lc} 
Body Part Affected & $\mathrm{n}(\%)$ \\
\hline All parts of body (more than 50\% of body) & $65(17)$ \\
Ankle & $6(2)$
\end{tabular}




\begin{tabular}{lc} 
Arm, lower (not including elbow or wrist) & $7(2)$ \\
Arm, upper & $2(1)$ \\
Ear & $127(34)$ \\
Elbow & $3(1)$ \\
Eye & $13(3)$ \\
Face (including eyelid, eye area and nose) & $6(2)$ \\
Finger & $8(2)$ \\
Foot & $15(4)$ \\
Hand & $9(2)$ \\
Head & $18(18)$ \\
Internal (use with aspiration and ingestion) & $2(1)$ \\
Knee & $9(2)$ \\
Leg, lower (not including knee or ankle) & $18(5)$ \\
Leg, upper & $1(0)$ \\
Mouth (including lips, tongue and teeth) & $2(1)$ \\
Neck & $2(1)$ \\
Shoulder (including clavicle, collarbone) & $15(4)$ \\
Toe & $4(1)$ \\
Trunk, lower & $10(3)$ \\
Trunk, upper (not including shoulders) & $35(9)$ \\
Wrist & $1(0)$ \\
\hline Total & $378(100)$ \\
\hline
\end{tabular}

Table 4 presents the disposition of patients following diagnosis. The majority (80\%) were treated and released or released without treatment. Less than $1 \%$ were dead on arrival or died in the ED. It is unknown how many later died as a result of their injuries.

Table 4: Disposition following diagnosis $(n=378)$

\begin{tabular}{lc}
\hline Disposition & $\mathrm{n}(\%)$ \\
\hline Treated and released, or examined and released without treatment & $305(81)$ \\
Treated and transferred to another hospital & $24(6)$ \\
Treated and admitted for hospitalization (within same facility) & $33(9)$ \\
Held for observation (includes admitted for observation) & $5(1)$ \\
Left without being seen/Left against medical advice & $8(2)$ \\
Fatality, including DOA, died in the ED & $3(1)$ \\
\hline Total & $378(100)$ \\
\hline
\end{tabular}

Regarding the location where each injury occurred, $332(88 \%)$ occurred at places of recreation/sports, $11(3 \%)$ at other public property, six (2\%) in homes and $29(8 \%)$ elsewhere or not recorded. 


\section{Canada}

Between the period of April 1, 1990 and December 31, 2015, 98 cases of scuba-related injuries were identified in the CHIRPP's data holdings. Of these, 28 cases were among patients aged 3-17 years (39-215 months of age), and 70 cases were among patients aged 1862 years (Table 5). An average of 3.8 cases were reported each year.

For the period 1990-2015, the rate of scuba-related injuries among CHIRPP records, among patients aged $3-17$ years $(39-215$ months $)$ is 1.5 per $10^{5}$ cases $\left[(28 / 1,830,213)^{*} 10^{5}\right]$; the rate of scuba related-injuries among CHIRPP records among patients 18-62 years is 16.5 per $10^{5}$ cases $\left[(70 / 423,961)^{*} 10^{5}\right]$.

Table 5. Frequency of emergency department presentations for scuba-related injuries, CHIRPP 1990-2015 , all ages

\begin{tabular}{|c|c|c|c|c|}
\hline & \multicolumn{2}{|c|}{ patients $<18$ years of age } & \multicolumn{2}{|c|}{ patients $>=18$ years of age } \\
\hline & *Scuba diving-related & $* *$ Non-diving related & *Scuba diving-related & $* *$ Non-diving related \\
\hline & 14 & 14 & 60 & 10 \\
\hline Total & \multicolumn{2}{|c|}{28} & \multicolumn{2}{|c|}{70} \\
\hline \multicolumn{5}{|c|}{$\begin{array}{l}\text { a Some information for the years } 2011-2015 \text { is still being entered into the electronic CHIRPP system. } \\
{ }^{*} \text { Injury sustained while diving, or while entering or exiting the water. } \\
{ }^{* *} \text { Injury was related to scuba diving or its equipment but did not occur while diving or exiting the water. Examples } \\
\text { include sunburn, falling over scuba tank in the garage, injury on scuba boat during scuba-related outing, injured } \\
\text { while misusing/playing with scuba equipment, etc. }\end{array}$} \\
\hline
\end{tabular}

\section{Morbidity and mortality rates}

Given there were 306,174,386 dives made by 30,444,000 US residents 2006-2015 (Table 1) and during that period there were 563 recreational diving deaths, then the fatality rate among US recreational divers is 0.18 per $10^{5}$ dives (95\% CI 0.16-0.21) and 1.8 per $10^{5}$ diver-years (95\% CI 1.49-2.21). There were 658 total diving deaths in the US 2006-2015 (Table 1) and 13,943 ED presentations in the US for scuba-related causes, giving a ratio of 47 deaths for every 1,000 ED presentations (95\% CI 26-69). That this figure is far higher than the raw, unweighted rate of 3/378 (7.9/1000) presented in Table 4 suggests the majority of diving fatalities occur outside of the ED.

\section{DISCUSSION}


It is important to know how common morbidity and mortality are in recreational diving for a number of reasons including a) to identify which sub-groups of divers are at elevated risk of injury or death, in support of the development of preventive interventions and b) to enable adequate insurance to be offered at reasonable expense, in support of hyperbaric and other medical treatment when required. In the US scuba-related injuries accounted for an estimated 13,943 out of $140,624,966$ ED presentations, or 9.9 per $10^{5}$. In Canada, there were 2,888,265 ED presentations in the CHIRPP database over 25 years, and the prevalence of scuba-related injuries among patients aged 3-62 was 4.3 per $10^{5}$ presentations. The following limitations are noted: Injuries described by the CHIRPP do not represent all injuries in Canada, as the CHIRPP contains only a sample of Canadian hospitals. Moreover, older teens and adults are underrepresented because most CHIRPP hospitals are pediatric and located in major cities. Given the relative rarity of scuba-related injuries in the CHIRPP, the number of cases captured can be subject to random variation due to a small sample size. As such, these results must be interpreted with caution. Fatal injuries are also under-represented in the CHIRPP database because the emergency department data do not capture people who died before they could be taken to hospital or those who died after being admitted. Among adults the scubarelated presentation rate was 16.5 cases per $10^{5}$, more than ten times that among children presenting to the ED. Recent reports from the SFIA suggest only around $15 \%$ of all US divers are younger than 18 years old. ${ }^{1}$ If this were taken into account then the presentation rates among adults may have been closer between the USA and Canada. In Canada and the US it appears likely that around only one out of every 10,000 ED presentations is due to a scubarelated injury, and the monthly distribution of these follow both the distribution of diving fatalities and non-fatal incidents reported to DAN. ${ }^{3}$ Not all presentations at the ER are included in the NEISS data, for example chronic diseases are not. Therefore, the true prevalence of scuba injuries among ER presentations is likely even lower than one in 10,000. DAN staff a 24/7 medical services call-centre offering free consult assistance to receiving ER staff unfamiliar with diving injuries.

That $75 \%$ of divers presenting to the ED are male is slightly higher than other studies report, for example $64 \%$ among DAN members ${ }^{12}, 64 \%$ among US recreational divers, ${ }^{1}$ and $70 \%$ among 4,711 (mainly US) recreational divers, ${ }^{24}$ but is lower than found among 333 US or Canadian recreational diving fatalities $\left(80 \%\right.$ male) ${ }^{3}$ It is, therefore, possible that male divers are over-represented in diving morbidity and mortality, perhaps due to greater exposure. The SFIA reported that, while male divers account for $64 \%$ of the total US recreational diving 
population, they make up $72 \%$ of those who dive $>7$ times per year. ${ }^{1}$ With mean ages of 37 and 41 years for injured males and females respectively, patients at the ED for scuba-related injuries were about the same age as found in 4,711 recreational divers (mean age 42), Danish diving fatalities (mean age 39) and in Croatian diving fatalities (mean age 38), ${ }^{24-26}$ slightly older than French divers presenting for hyperbaric treatment at a hospital near Paris between 1993-2003 (mean age 34 years), ${ }^{27}$ and slightly younger than insured DAN members in 2006 (mean age 44 and 42 years for males and females respectively). ${ }^{12}$

The types of injuries seen at the ED are typical of those reported to DAN's emergency call center, ${ }^{3}$ with ears clearly the most commonly affected body part (Table 3 ). It may be reassuring that four out of five victims of a scuba-related injury will be discharged either following treatment at the ED or without any treatment at all (Table 4), but that there are 47 deaths in the US for every 1,000 ER presentations speaks to the relatively unforgiving environment in which scuba diving takes place.

The mortality rate of 0.18 per $10^{5}$ dives is less than half that reported in Australia, but differing methodology may account for this discrepancy, rather than any real difference in risk. ${ }^{13}$ The mortality rate of 1.8 per $10^{5}$ divers per year lies between those found in British Columbia and Okinawa by counting air fills. This rate is comparable to many other outdoor recreations but direct comparisons are not possible due to variation in data sources and methodologies. It is substantially lower than that reported among DAN-insured members who were largely based in the US and Canada but DAN members are known to average 25 dives per year which is 2.5 times the exposure found by SFIA, and they were significantly older than the divers in this study and age is a known risk factor for death while recreational scuba diving. ${ }^{12}$ The process of certification for scuba diving is relatively uniform worldwide, with only minor regional differences. Once certified there are usually no requirements for the maintenance of that certification. Unlike, for example, a driver's license, there is usually no requirement for regular re-testing of skills.

The limitations of this study include that the NEISS employ a weighted sampling frame geared to represent the population of US hospitals, but that scuba diving is a geographically concentrated sport confined to locations with access to popular dive sites and, therefore, the NEISS may not accurately reflect the true distribution of scuba-related injuries across the US. The actual mortality rate may be higher than reported here because it is not certain that every diving fatality that occurred in the US between 2006-2015 is included in the DAN fatality 
database. Many diving injuries do not result in presentation to the ED and, therefore, the overall burden of injury attributable to recreational scuba diving is likely greater than that resulting in presentations to the ED or death. Also, many of the injuries listed in Table 2 had raw counts of less than 20 cases and, therefore, estimates of their annual incidence cannot be reliably made. As with calls to the DAN Emergency Helpline, barotrauma and DCS were the most common injuries seen at the ED. Lastly, it should also be remembered that not all the dives estimated to have been made by US residents were likely made within the US and also that many dives are made in the US by visiting divers, and country of residence is not noted in the NEISS data.

\section{ACKNOWLEDGEMENTS}

The authors thank Thomas Schroeder at the Division of Hazard and Injury Data Systems, U.S. Consumer Product Safety Commission for his invaluable assistance in calculating the confidence intervals around the NEISS data, and Keith Storey at Sports Marketing Surveys. Julie Gilchrist at the Centers for Disease Control \& Prevention was also very helpful during the design phase of this project.

Funding: This research did not receive any specific grant from funding agencies in the public, commercial, or not-for-profit sectors.

Competing interests: The authors declare that they have no competing interest. All authors approve the submitted version of this manuscript.

Ethical approval: Both the NEISS and SFIA data are publically available, the DAN fatality data was collected and analysed under approval from the Divers Alert Network Institutional Review Board (Approval \#011-016) and the CHIRPP data were de-identified before analysis, therefore, the CHIRPP determined separate IRB approval was not required in this instance. All procedures performed in studies involving human participants were in accordance with the ethical standards of the Divers Alert Network Institutional Review Board and with the 1964 Helsinki declaration and its later amendments or comparable ethical standards.

\section{REFERENCES}


1. Sports and Fitness Industry Association. Participation in recreational diving report. Silver Spring, MD.: Sports and Fitness Industry Association.2015.

2. Denoble PJ, Caruso JL, Dear Gde L, Pieper CF, Vann RD, Dear GdL. Common causes of open-circuit recreational diving fatalities. Undersea Hyperb Med. 2008;35(6):393406.

3. Buzzacott P, Trout B, Caruso J, Nelson C, Denoble P, Nord D, et al. DAN Annual Diving Report 2012-2015 Edition: Divers Alert Network. 2015.

4. Buzzacott PL. The epidemiology of injury in scuba diving. In: Caine D, Heggie T, editors. Epidemiology of Injury in Adventure and Extreme Sports. Basel, Switzerland: Kager; 2012. p. 57-79.

5. Lippmann J. Review of scuba diving fatalities and decompression illness in Australia. Diving Hyperb Med. 2008;38(2):71-8.

6. Ladd G, Stepan V, Stevens L. The Abacus Project: establishing the risk of recreational scuba death and decompression illness. South Pacific Underwater Medicine Society Journal. 2002;32(3):124-8.

7. Arness MK. Scuba decompression illness and diving fatalities in an overseas military community. Aviat Space Environ Med. 1997;68(4):325-33.

8. Gilliam B. Evaluation of decompression sickness incidence in multi-day repetative diving for 77,680 sport dives. South Pacific Underwater Medicine Society Journal. 1992;22:24-30.

9. Wilmshurst P, Allen C, Parish T. Incidence of decompression illness in amateur scuba divers. Health Trends. 19941994 -;26(4):116-8.

10. Nakayama H, Shibayama M, Yamami N, Togawa S, Takahashi M, Mano Y. Decompression sickness and recreational scuba divers. Emergency Medicine Journal. 2003;20(4):332-4.

11. Hart AJ, White SA, Conboy PJ, Bodiwala G, Quinton D. Open water scuba diving accidents at Leicester: five years' experience. J Accid Emerg Med. 1999;16(3):198-200.

12. Denoble PJ, Pollock NW, Vaithiyanathan P, Caruso JL, Dovenbarger JA, Vann RD.

Scuba injury death rate among insured DAN members. Diving Hyperb Med. 2008;38(4):1828 .

13. Lippmann J, Stevenson C, McD. TD, Williams J. Estimating the risk of a scuba diving fatality in Australia. Diving Hyperb Med. 2016;46(4):241-46.

14. Conn JM, Annest JL, Gilchrist J, Ryan GW. Injuries from paintball game related activities in the United States, 1997-2001. Injury Prevention. 2004;10:139-43.

15. Klick C, Jones CMC, Adler D. Surfing USA: an epidemiological study of surfing injuries presenting to US EDs 2002 to 2013. American Journal of Emergency Medicine. 2016;34:1491-96.

16. Heilbronn C, Svider P, Folbe A, Shkoukani M, Carron M, Eloy J, et al. Burns in the head and neck: a national representative analysis of Emergency Department visits. The Laryngoscope. 2015;125:1573-78.

17. Consumer Product Safety Commission. NEISS Coding Manual January 2016. 2016; Available from: https://www.cpsc.gov/s3fspublic/pdfs/blk_media_2016NonTraumaNEISSCodingManual.pdf. 
18. Centers for Disease Control and Prevention. Definition for WISQARS Nonfatal. Centers for Disease Control and Prevention; 2016 [cited 2016 7th December]; Available from: http://www.cdc.gov/NCIPC/wisqars/nonfatal/definitions.htm.

19. Ting DK, Brison RJ. Injuries in recreational curling include head injuries and may be prevented by using proper footwear. Health promotion and chronic disease prevention in Canada : research, policy and practice. 2015;35(2):29-34.

20. Vanlaar W, McAteer H, Brown S, Crain J, McFaull S, Hing MM. Injuries related to off-road vehicles in Canada. Accident; analysis and prevention. 2015;75:264-71.

21. McPherson M, Pickett W. Characteristics of martial art injuries in a defined Canadian population: a descriptive epidemiological study. BMC Public Health. 2010 Dec 30;10:795.

22. Crain J, McFaull S, Thompson W, Skinner R, Do MT, Frechette M, et al. Status report - The Canadian Hospitals Injury Reporting and Prevention Program: a dynamic and innovative injury surveillance system. Health promotion and chronic disease prevention in Canada : research, policy and practice. 2016;36(6):112-7.

23. US Census Bureau. 2016; Available from: https://www.census.gov/quickfacts/table/PST045215/00.

24. Buzzacott P, Denoble P, Dunford R, Vann R. Dive problems and risk factors for diving morbidity. Diving Hyperb Med. 2009;39(4):205-9.

25. Stemberga V, Petaros A, Rasic V, Azman J, Sosa I, Coklo M, et al. Dive-related fatalities among tourist and local divers in the northern Croatian littoral (1980-2010). J Travel Med. 2013;20(2):101-6.

26. Vinkel J, Bak P, Hyldegaard O. Danish diving-related fatalities 1999-2012. Diving Hyperb Med. 2016;46(3):142-9.

27. Bessereau J, Genotelle N, Brun P-M, Aboab J, Antona M, Chenaitia H, et al.

Decompression sickness in urban divers in France. Int Marit Health. 2012;63(3):170-3. 


\section{Tables Legend}

Table 1: Estimated number of divers, dives, fatalities and ED presentations in the US 20062015

Table 2: Diagnoses by raw number $(n=378)$

Table 3: Body part affected by scuba-related injury $(n=378)$

Table 4: Disposition following diagnosis $(n=378)$

Table 5: Frequency of emergency department presentations for scuba-related injuries, CHIRPP 1990-2015 , all ages 